\title{
TRADUCCIÓN DE LOS REFERENTES CULTURALES EN EL DOBLAJE DE LA SERIE “ÉRASE UNA VEZ... EL HOMBRE” AL ESPAÑOL Carmen Martín Fernández Universidad de Málaga
}

\begin{abstract}
In the present article, we will analyse the challenges presented by audio visual translation in historical and popular programmes aimed at younger age audiences. This study focuses on two representative elements from the episode of The French Revolution in Castilian Spanish and in Latin American Spanish dubbed version of the French series 'Was upon a time... Man'. Thus, the objective will be to observe the translation difficulties and its solutions in both the cultures and target languages.
\end{abstract}

KEYWORDS: AVT, French- Spanish dubbing, TV series, cultural references.

\section{RESUMEN}

En el presente artículo analizaremos las dificultades que presenta la traducción audiovisual de productos de divulgación histórica para un público infantil y juvenil. El estudio se centra en dos elementos representativos del capítulo «La Revolución francesa» de la serie Érase una vez... el hombre en francés y en las versiones en español peninsular y de Latinoamérica. El objetivo será observar los problemas de traducción y las soluciones que las dos culturas y lenguas meta ofrecen.

PALABRAS CLAVE: traducción audiovisual, doblaje francés-español, series de televisión, referentes culturales.

\section{INTRODUCCIÓN}

La televisión se he convertido en uno de los medios de mayor alcance en la sociedad sin importar edad o género. Todos tenemos algo de esa "cultura televisiva", que no son sino huellas de una u otra sociedad, de su historia, de sus personajes. Dicha cultura nos traslada, a través de cada uno de los diversos productos en los que se subdividen, información, valores, creencias, ideología, 
en definitiva, la visión del mundo según autor del producto. Sin embargo, cuando se trata de productos extranjeros, dicha cultura nos llega a través de sus traducciones. Por tanto, será la modalidad audiovisual la encargada de hacernos llegar los productos audiovisuales en un código accesible a nuestras pantallas, ya sean de televisión, cine, ordenador y tantos otros medios que hoy en día vemos gracias a las nuevas tecnologías.

En el presente artículo abordaremos el caso de la traducción audiovisual de un producto televisivo de divulgación histórica para un público infantil y juvenil en su versión doblada de francés a español peninsular y de América. Se trata de la serie Érase una vez... el hombre y elegiremos uno de sus capítulos: La Revolución francesa.

Los motivos que nos llevan a considerar dicho producto y dichas combinaciones lingüísticas son comparar dos traducciones del mismo producto original y analizar cómo se han resuelto los problemas de traducción en dichas culturas (nos referimos a los casos de España y Latinoamérica, donde la distancia cultural existente entre ellas y con respecto a Francia podría haber dado lugar a soluciones de traducción diferentes). Creemos además que este episodio contiene elementos "muy franceses" e interesantes, por tanto, para la investigación.

Dado que el material con el que trabajaremos es de divulgación histórica, consideramos pertinente contar con una definición de Historia a partir de la cual podamos decidir con qué tipo de referentes podremos encontrarnos en el corpus. Tomamos dos acepciones del DRAE, la primera: $f$. Narración y exposición de los acontecimientos pasados y dignos de memoria, sean públicos o privados. Y la cuarta: f. Conjunto de los sucesos o hechos politicos, sociales, económicos, culturales, etc., de un pueblo o de una nación.

A partir de lo anterior, podemos determinar que la historia (entendamos que el historiador) narra y expone acontecimientos pasados y que dichos acontecimientos podrán ser de tipo político, económicos, cultural. Proponemos así los siguientes elementos para el análisis:

- Los nombres propios. Observaremos y clasificaremos las estrategias usadas por el traductor en el traslado los nombres propios a las dos culturas meta. Para ordenar dichos elementos léxicos y culturales de nuestro corpus utilizamos la clasificación de nombres propios que propone Virgilio Moya (2000) porque nos permite incluir muchos de los elementos que aparecen en el capítulo. Nos referimos a los antropónimos, los topónimos, la onomástica política y, por último, los nombres de monedas.

- La presencia de la mujer y sus enunciados. Expondremos cuáles han sido, a nuestro parecer, las estrategias de traducción utilizadas para elementos culturales como el contenido político e ideológico del capítulo. A lo largo del capítulo veremos que el discurso histórico está 
cargado de ideología de la época revolucionaria. En particular abordaremos las traducciones relacionadas con los personajes femeninos. Para ello hemos extraído los discursos femeninos, cotejado las versiones traducidas, y seleccionado los elementos que han sufrido alteraciones en la transferencia lingüística.

\section{LOS GÉNEROS AUDIOVISUALES Y LA TRANSFERENCIA LINGÜÍSTICA}

Si partimos del concepto general según el cual la traducción audiovisual, en palabras de Chaume (2004: 31), incluye «las transferencias de textos verbo-icónicos de cualquier tipo transmitidos a través de los canales acústico y visual en cualquiera de los medios físicos o soportes existentes en la actualidad» necesitaremos conocer cuáles son los textos verbo-icónicos que se transmiten en los diferentes canales para ver las diferencias existentes entre ellos. Es decir, hemos de conocer y clasificar los géneros audiovisuales.

Para ello utilizaremos, como tantos otros estudios en traducción audiovisual, la clasificación de Agost (1999). Estos podrían reunirse en cuatro grupos: en primer lugar, los géneros dramáticos, cuya principal función es narrar un hecho. Éstos pueden dar lugar a múltiples géneros y subgéneros: las películas (románticas, documentales), las series (de adolescentes, de adultos), los dibujos animados (películas animadas, series de dibujos). A continuación, los géneros informativos, como los documentales, reportajes, cuya principal función es la de narrar y describir; los debates, entrevistas, etc. Otro género audiovisual es el publicitario, que lo constituyen los anuncios, la venta por televisión y tantos otros cuyo objetivo es el de instruir y exponer. Por último, el género de entretenimiento, que incluye los programas de humor, los concursos, entre otros. Las funciones de este género audiovisual serán narrar, instruir y, en cualquier caso, divertir.

Consideramos, por tanto, que Érase una vez... el hombre se incluye dentro del género dramático con algunas características del género informativo ya que por un lado, es una serie de dibujos animados destinada a un público infantil y juvenil y por otro, expone hechos pasados de la historia de diferentes países.

\section{METODOLOGÍA}

Puesto que vamos a analizar algunos de los múltiples elementos culturales del capítulo, hemos de partir de una definición de elementos culturales. Entendemos que, de entre las muchas existentes, la que ofrece Nord es de gran utilidad. Según la autora un culturema es «un fenómeno social de una 
cultura $\mathrm{X}$ que es entendido como relevante por los miembros de esa cultura y que, comparado con un fenómeno correspondiente de una cultura $\mathrm{Y}$, es percibido como específico de la cultura X» (cit. por Hurtado, 2007: 611). La traducción de dichos culturemas o referentes culturales presentarán numerosas dificultades, que además se intensificarán con la lejanía de las culturas en juego. Esto es, partimos de la idea de que encontraremos versiones diferentes entre la española y la latinoamericana en, al menos, dichos referentes culturales.

Nuestro objetivo, pues, será observar cuáles han sido las estrategias de traducción llevadas a cabo para tales culturemas, que en este artículo se reducirán a nombres propios, una vez hayamos establecido unas pautas para extraer dichos elementos. Para ello, hemos recurrido a la obra de Virgilio Moya (2000), «La traducción de los nombres propios», que distingue entre los antropónimos, los topónimos, la onomástica política y las monedas. Recordemos que coincide con los elementos que definen a la Historia y que citamos anteriormente (conjunto de los sucesos o hechos políticos, sociales, económicos, culturales, etc., de un pueblo o de una nación).

Para la clasificación de las estrategias utilizaremos el modelo de Gisela Marcelo (2007), del que sólo extraeremos tres de sus cuatro procedimientos de traducción:

- Domesticación: consiste en eliminar los elementos del texto origen (TO) que puedan resultar extraños para la cultura de llegada. Para ello, se sustituyen los elementos desconocidos por otros propios de la cultura del texto meta (TM).

- Extranjerización: es la estrategia traductora opuesta a la anterior. Los elementos propios de la cultura del TM se mantienen en la traducción del TO.

- Neutralización: consiste en trasladar un elemento de la cultura del TO a la cultura del TM sin marcas culturales, bien sea por desconocimiento del traductor o por conveniencia en la traducción.

\section{APUNTES SOBRE ÉRASE UNA VEZ... Y SU RECEPCIÓN}

La colección Érase una vez... se compone de seis series, que comienza en 1978 con Érase un vez...el hombre hasta 1996 con Érase una vez...los exploradores. Entre ellas se encuentra la también famosa Érase una vez... el cuerpo bumano creada en 1987. Todas ellas están realizadas por el francés Albert Barillé y nos cuentan la historia de la humanidad desde el origen del Universo hasta el final del siglo XX en veintiséis capítulos de veintiséis minutos cada uno.

La obra de Barillé tuvo una amplia difusión no sólo en Europa, sino en América, Israel o Japón ya que contó con la participación de éstas y de otras cadenas de televisión públicas, entre ellas, Televisión Española, donde se emitió 
durante los años ochenta y noventa. Fue TVE-1 quien contó con la versión doblada en español peninsular mientras que la editorial Planeta (Planeta de Agostini) dispuso de la versión latinoamericana y la comercializó tanto en nuestro país como en Latinoamérica en VHS y posteriormente en DVD junto con unos libros o fascículos, siempre por entregas. De hecho, todavía hoy podemos adquirir la colección con Planeta, aunque en su versión latinoamericana, no española.

\section{LA TRADUCCIÓN DE LOS REFERENTES CULTURALES EN LA SERIE ÉRASE UN VEZ...EL HOMBRE}

\subsection{TRADUCCIÓN DE LOS NOMBRES PROPIOS}

Tal y como expusimos anteriormente y sin ánimo de ser repetitivos, nuestra serie se incluye dentro del género dramático con algunas características del informativo. Tendremos por ello que diferenciar entre los elementos culturales que pretenden informarnos o narrarnos una historia real, y los que quieren sencillamente entretenernos o contarnos una historia ficticia, propia del género dramático.

Los referentes del capítulo que hemos extraído en nuestro análisis pertenecen, los hemos ordenado situando en primer lugar la versión original francesa (TO), en segundo lugar la versión traducida al español peninsular (TM1) y en tercer lugar la versión latinoamericana (TM2). Éstos estarán relacionados principalmente con aspectos históricos, por su abundancia en el capítulo.

\subsubsection{Los antropónimos: reales y ficticios}

Los nombres de los personajes reales, que forman parte de la Historia y que según podemos comprobar se suelen traducir o naturalizar en las dos versiones por tratarse de nombres de la realeza y ampliamente conocidos:

\begin{tabular}{lll} 
TO & TM1 & TM2 \\
\hline Joséphine & Josefina & Josefina \\
Louis XVI & Luis XVI & Luis XVI
\end{tabular}

Por el contrario, los ejemplos que mostramos a continuación no siguen estrategias similares en los dos TM. La versión latinoamericana tiende a domesticar algunos de los referentes, como las Merveilleuses y los Incroyables, 
conocidos personajes de la Revolución francesa, mientras que la versión española (entendemos por española, de España) extranjeriza más:

\begin{tabular}{lll} 
TO & TM1 & TM2 \\
\hline Madame Tallien & Madame Tallien & La señora Tallien \\
Maximilian & Maximiliano & Max \\
Merveilleuses et & Las Merveilleuses y & Damas maravillosas y \\
Incroyables & los Incroyables & bellas \\
Monsieur Véto & Señor Veto & Señor
\end{tabular}

En el último ejemplo, el TM2 omite «veto» (nombre por el que se conocía a Luis XVI) para quizás prescindir de información que considera complicada para los receptores.

En segundo lugar, los nombres de los personajes ficticios, propios del género dramático, que aparecen en todos los capítulos y cuyos nombres, en ocasiones, dicen algo de ellos:

\begin{tabular}{lll} 
TO & TM1 & TM2 \\
\hline Maestro & Maestro & Maestro \\
Pierrette & Flor & Pierrette \\
Pierrot & Pedrito & Pierrot
\end{tabular}

Vemos que, por lo general, la versión latinoamericana conserva los nombres de los personajes en la versión original mientras que el TM1 los traduce.

\subsubsection{Los topónimos}

Los topónimos del capítulo son todos reales, se han traducido según los topónimos acuñados en ambas versiones, cuando los ha habido, y se han evitado extranjerismos:

\begin{tabular}{lll} 
TO & TM1 & TM2 \\
\hline La Bastille & La Bastilla & La Bastilla \\
Les Invalides & Los Inválidos & Los Inválidos
\end{tabular}


Los topónimos europeos, en este y en otros capítulos, se han traducido o naturalizado. Por ello, no mostraremos más que estos dos ejemplos que lo ilustran para pasar a otros elementos que sí presentan diferencias en la traducción.

\subsubsection{La onomástica política}

En el caso de los nombres relacionados con la política vemos que se han utilizado las traducciones conocidas y acuñadas en ambas culturas meta:

\begin{tabular}{lll} 
TO & TM1 & TM2 \\
\hline L'Assemblée & La Asamblea & La Asamblea \\
Nationale & Nacional & Nacional \\
Le Directoire & El Directorio & El Directorio
\end{tabular}

Pese a que ha habido homogeneidad en las soluciones de traducción, también hemos observado diferencias que por lo general coinciden con estos casos: la neutralización del referente al eliminar una o varias partes de éste o bien la omisión total del mismo.

En primer lugar, observamos que Milice bourgeoise (o Milice Nationale, como también se la conoce) en el TM2 se traduce simplemente como «milicia». Omiten el concepto de burguesía y consiguen neutralizar la traducción.

\begin{tabular}{lll} 
TO & TM1 & TM2 \\
\hline Milice bourgeoise & Milicia burguesa & Milicia
\end{tabular}

En segundo lugar, la traducción de la Déclaration des Droits de l'Homme et $d u$ Citoyen, uno de los hitos de la Revolución francesa, que el TM1 omite un referente cultural importante le Citoyen o «Ciudadano» y queda en cierto modo neutralizada la versión española. No vemos que sea necesario, puesto que «la Declaración de los Derechos del Hombre y del Ciudadano» existe como traducción acuñada en nuestro país. 


\begin{tabular}{lll} 
TO & TM1 & TM2 \\
\hline La Déclaration des & Los Derechos del & La Declaración de los \\
Droits de l'Homme & $\begin{array}{l}\text { Derechos del } \\
\text { et du Citoyen }\end{array}$ & Hombre \\
Ciudadano
\end{tabular}

En tercer lugar, el caso de Le Serment du Jeu de Paume, o como aparece en nuestro texto, le Jeu de Paume, se ha eliminado de la versión latinoamericana, y no en la española suponemos que para evitar cargar el texto con información.

\begin{tabular}{lll} 
TO & TM1 & TM2 \\
\hline Jeu de Paume & Juego de Pelota & -
\end{tabular}

\subsubsection{Las monedas}

Para el siguiente apartado aportamos únicamente el siguiente ejemplo, pero consideramos que nos ayuda para extraer conclusiones:

\begin{tabular}{lll} 
TO & TM1 & TM2 \\
\hline Denier & Céntimo & $\begin{array}{l}\text { Dinero, monedas, } \\
\text { libra }\end{array}$
\end{tabular}

En el diccionario «La Revolución francesa en clave lingüística y textual» que nos sirve de referencia leemos la siguiente definición de denier: «antigua moneda de cobre equivalente a la doceava parte del sou (perra chica o cinco céntimos).»Y según el TLF1, la palabra denier se utilizaba en Europa occidental y en Francia hasta el siglo XIX. No obstante, se ha preferido domesticar en ambas versiones y explicitar (sólo en el caso del TM2) para acercarlo al lector.

Exceptuando los casos de la traducción de los nombres de los personajes de ficción, que serían los comunes del género dramático, todos los demás ejemplos de traducción de referentes políticos, personajes históricos y las monedas podríamos decir que pertenecen o que, a priori, habrían de tratarse como propios del género informativo, como narración de una historia real donde prevalecen los conceptos, los hechos.

1 Le TLFi es un diccionario informatizado realizado a partir del Trésor de la Langue Française (1971-1994). 
Hasta ahora hemos observado distintas soluciones de traducción atendiendo, suponemos, a las necesidades del receptor. Es decir, cuando la versión latinoamericana ha considerado que debía eliminar algún referente para no cargar de información el texto o modificarlo para que se adaptase al género infantil, lo ha hecho. El anterior ejemplo, la traducción de la voz francesa denier, no es sino un ejemplo más.

\subsection{LA TRADUCCIÓN DEL PAPEL DE LA MUJER EN EL CAPÍTULO}

Ana Ballester (2001) observó que en el doblaje al español de Sangre y Arena los traductores solían autocensurarse mediante el uso de eufemismos, omisiones, sustituciones para suavizar la versión meta por las claras presiones ideológicas del momento. En el presente estudio, pese a las diferencias entre la investigación de Ballester y la nuestra, hemos detectado la presencia de algunas alteraciones en la traducción similares a su estudio, en nuestro caso, alteraciones en el género (de femenino a masculino o a neutro) y alteraciones en la traducción con respecto al sentido original del texto que provoca una eliminación del papel protagonista de la mujer.

Quizás debamos aclarar previamente que en el capítulo las mujeres son unos de los motores de la Revolución. Hay constantes alusiones a personajes históricos tan relevantes como, por ejemplo, Olimpia de Gouges, gracias a la cual se firmó la Declaración de los Derechos de la Mujer y de la Ciudadana. Por otra parte, durante el análisis de las versiones traducidas del capítulo, hemos observado que la versión latinoamericana es por lo general bastante «calcada» al original, en lo que respecta a los juegos de palabras, sintaxis de las frases, etc., conclusión que no coincide con la estrategia de traducción utilizada en el caso de las intervenciones de la mujer, las cuales se han modificado total o parcialmente en algunos momentos del capítulo latinoamericano.

De este modo, pasamos a los dos casos que nos hemos encontrado de alteración del TO y que ilustramos con algunos ejemplos:

\subsubsection{Alteración o cambio de género}

El primer caso, en el enunciado se pasa de género femenino a masculino o neutro. Hemos subrayado los elementos del TM1 y TM2 que muestran las diferencias. Las primeras alteraciones las observamos en una escena que tiene lugar durante la toma de la Bastilla, en la que Flor, la protagonista, llama a todas las mujeres que aparecen en la imagen e imitando el cuadro de Delacroix, La libertad guiando al pueblo, para que continúen con la ofensiva: 
TO

Pierrette : Allons sœurs, montrons-leur ce que nous savons faire, allons, un peu de courage !

TM1

Flor:

¡Vamos, hermanos! ¡Adelante compañeras, hay que luchar hasta el fin! ¡Vamos, valor, hermanas, seguidme!

TM2

Pierrette: ¡Vamos, hermanos! ¡Demostremos los que sabemos hacer, demostremos que somos valientes!

En el siguiente ejemplo, una de las protagonistas del capítulo, Olimpia de Gouges, exclama a Robespierre en el Parlamento:

$\mathrm{TO}$

Olympe : Et les citoyennes, alors ? Parlez-en donc, ne sont-elles là que pour le délassement du Citoyen et pour torcher les mômes, ou seulement pour faire la queue devant les boulangeries? Nous réclamons, nous exigeons une Déclaration des Droits de la Femme et de la Citoyenne.

TM1

Olimpia: Y las ciudadanas, ¿qué? Aclaremos eso, ¿ ¿ $\underline{\text { Sólo estamos aquí para }}$ recreo del Ciudadano y para ocuparnos de los críos? ¿O para hacer cola día y noche delante de las panaderías? Nosotras reclamamos, exigimos una Declaración de los Derechos de la Mujer y de la Ciudadana.

TM2

Olimpia: Y entonces, los ciudadanos, hablemos de ellos, ¿no están aquí los ciudadanos para exigir sus derechos y para quitar los antiguos? ¿O para esperar el pan delante de las panaderías? Reclamamos y exigimos una Declaración de los Derechos de la Mujer y de la Ciudadanía.

\subsubsection{Alteración del sentido de la frase}

El segundo caso, la eliminación del protagonismo de la mujer, cuyos ejemplos son los dos que incluimos a continuación. El primero, en el que el 
ENTREC ULTURAS Número 1. ISSN: 1989-5097. Fecha de public ación: 27-03-2009

Maestro entra en la casa de sus amigos y encuentra a los chicos corriendo por las escaleras y les pregunta:

$\mathrm{TO}$

Maestro : Mais où courrez-vous comme ça?

Pierrot: On va voir manifester maman, allez, viens avec nous ! Allez, viens !

TM1

Maestro: ¿Adónde vais tan deprisa?

Pedrito: A ver a mamá, va a la manifestación. Ven con nosotros, anda. ¡Venga, vamos!

TM2

Maestro: ¿Pero por qué corres así?

Pierrot: ¡Vamos, ven con nosotros! ¡Ven, acompáñanos!

Quizás no resulte demasiado importante dicha eliminación, pero nos sorprende, más aún al observar como un minuto más tarde, Flor, que ha liderado una importante manifestación, mantiene la siguiente conversación con el Maestro:

TO

Pierrette : Oh! Oui, quelque part en mission probablement dans un café. Et je suppose qu'ils doivent refaire le monde devant un verre de vin rouge.

Maestro : Bravo pour ce que vous avez fait.

Pierrette : Merci. Et vous, Maestro, est-ce que vous avez fait du bon travail à l'Assemblée?

TM1

Flor: $\quad$ Sí, cumpliendo alguna misión pero en alguna taberna. Supongo que estarán arreglando el mundo delante de un vaso de vino.

Maestro: Has hablado muy bien esta tarde, Flor.

Flor: $\quad$ Gracias, y vosotros qué tal, Maestro, chabéis avanzado mucho en vuestros acuerdos? 
TM2

Pierrette: Sí, Maestro, posiblemente se reunieron en un café y supongo que estarán arreglando el mundo delante de un vaso de vino tinto.

Maestro: Espero que lo hayan arreglado bien.

Pierrette: Y dígame, Maestro, ¿usted hizo un buen trabajo en la Asamblea?

En este último caso, al igual que en los anteriores, si viéramos la imagen comprobaríamos que no se percibe dicha alteración. El texto es coherente en ambas versiones traducidas y la imagen, en especial en este último ejemplo, no contradice el texto, pero no es fiel a la versión original.

Según Hurtado (2007: 637), las estrategias de traducción son aquellas que el traductor utiliza, consciente o inconscientemente, para resolver los problemas que encuentra a lo largo del proceso y mejorar así su eficacia según sus necesidades. Nos preguntamos, por tanto, cuáles habrán sido las razones para motivar dichas soluciones de traducción

\section{CONCLUSIONES}

Las primeras conclusiones a las que llegamos corroboran nuestra hipótesis de partida. Suponíamos que habría diferencias notables en la traducción de algunos de los referentes culturales. Por una parte, los elementos propios de la Historia, más expositivos, se han visto domesticados y neutralizados (con algunas omisiones) con más frecuencia en la versión latinoamericana. Por otra parte, en lo que atañe a los elementos propios del género dramático, como son los personajes de ficción, hemos notado que el TM2 prefiere los nombres franceses para, suponemos, dar colorido al texto: Pierrette, Pierrot.

En lo que respecta al TM1, la versión española, ha mantenido más voces extranjeras y pese a que hemos observado cierta neutralización, ha recurrido a amplificaciones con más frecuencia que el TM2 en los elementos históricos, reales, mientas que para los personajes de ficción, nuestro país prefiere nombres españoles: Flor, Pedrito.

Por último, el análisis de los papeles femeninos en el capítulo. Una vez observados y clasificados los tipos de cambios de la versión latinoamericana, quedaría aún por realizar un mayor análisis para comprobar si efectivamente dichas alteraciones de las intervenciones femeninas han sido intencionadas o no y si se repiten en el resto de capítulos. 


\section{BIBLIOGRAFÍA}

Agost Canón, Rosa (1999): Traducción y doblaje: palabras, voces e imágenes. Barcelona, Ed. Ariel Practicum.

Ballester Casado, ANa Rosa: (2001): Traducción y nacionalismo. La recepción del cine americano en España a través del doblaje (1928-1948). Granada, Ed. Comares.

Cantera Ortiz de Urbina J., Ortega Arjonilla E. y Campos Plaza N. A. (2007): La Revolución francesa en clave lingüística y textual: Diccionario de términos y expresiones revolucionarios (francés-español), Granada, Método Ediciones.

Chaume Varela, Frederic (2004): Cine y traducción. Madrid, Ed. Cátedra.

Hurtado Albir, Amparo (2007): Traducción y Traductología. Introducción a la Traductología. $3^{\circ}$ ed., Madrid, Ed. Cátedra.

MARCELO Wirnitzer, Gisela (2007): Traducción de las referencias culturales en la literatura infantil y juvenil. Frankfurt, Peter Lang.

MoYA, VirgiLIO (2000) La traducción de los nombres propios. Madrid, Ed. Cátedra. 